
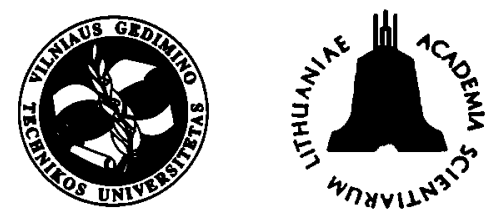

\author{
ISSN 1392-3730 \\ JOURNAL OF CIVIL ENGINEERING AND MANAGEMENT \\ http:/www.vtu.It/english/editions
}

2003, Vol IX, No 3, 214-217

\title{
TOPICAL ISSUES OF SYSTEMS ENGINEERING
}

\author{
Alexander Gusakov' ${ }^{1}$, Olga Ilina ${ }^{2}$, Ekaterina Kulikova ${ }^{3}$, Olga Melikhova ${ }^{4}$ \\ Moscow State University of Civil Engineering, \\ Yaroslavskoye sh., 26, Moscow, Russia \\ E-mail: mgsusapr@mtu.ru
}

Received 02 Apr 2003; accepted 19 June 2003

\begin{abstract}
The article deals with topical issues of systems engineering development which is considered as a scientificengineering methodology of effective design and functioning of construction systems and intersystem ties that are of great diversity and individuality. The authors investigate the processes of forming and selecting CAD information strategies, norms- and rule-making in construction sphere, methods of macrodesign of construction systems.
\end{abstract}

Keywords: systems engineering, computer-aided design (CAD), hardly formalised information, neural networks.

\section{Introduction}

Systems engineering in construction is a scientifictechnical discipline included in a complex and interrelations manner questions of design, creation, functioning and development of construction systems, ie systems formed for reaching predetermined results in construction $[1,2]$.

Appearance of systems engineering is closely connected with rapid developments of engineering activity during recent decades. According to calculations done by experts, if a number of interrelated organisations or elements multiplies by tens, a number of ties and hence management complexity multiplies by hundreds. We think about construction systems that now include not only traditional construction elements (building structures, machines, construction crews), but also elements of contemporary complicated organisational-economical and computer systems (economic mechanism, organisational management structures, computer-aided systems of planning, design, management) [3-6].

Organisation of construction systems and other complex systems design may be divided into two different stages: the stage of macrodesign when systems structure and its functional connections with outer environment are determined, and the stage of microdesign, when systems elements are constructed [7].

Taking into account the current level of systems engineering development, we see the following problems at the stage of macrodesign:

1. Forming and selecting CAD information strategies $[8,9]$.

2. Norms- and rule-making in information support of innovative development of construction [10].
3. Development of method of conceptual modelling of construction systems [7, 11, 12].

\section{Forming and selecting the $\mathrm{CAD}$ information strategies}

Contemporary CAD systems in construction are complex integrated systems allowing to form design decisions and evaluate them at early stage, to make economical calculations when selecting alternative design decisions based on ecology, social, organisational criteria of environment. An accurate analysis at early stage of design provides not only quality and demand of architecture and structuring works but also effectiveness of the whole project $[2,8]$.

Often CAD is a complex of professional software systems available on the market. And it is an important scientific and practical problem now to compare and select appropriate for every design organisation a set of software products that usually can be characterised by different structure, cost, adequacy, sources of receiving necessary and sufficient information to develop and operate CAD in every design company. By CAD information strategy we understand systems engineering-based selection of CAD hard- and software, information and organisational support of design company taking into consideration the company's perspective development $[3,13]$.

The main objective of development and implementation of CAD information strategy in a design organization is to facilitate an effective management of organisation, react to market dynamics, to support and promote competitive advantage [9].

A CAD project includes a complex of interrelated 
activities connected with forming, implementing and operating $\mathrm{CAD}$ within time, budget and quality constraints. CAD project management is a process oriented towards customer satisfaction and includes a coordination of financial, material and human resources at all the stages of project life cycle (Fig).

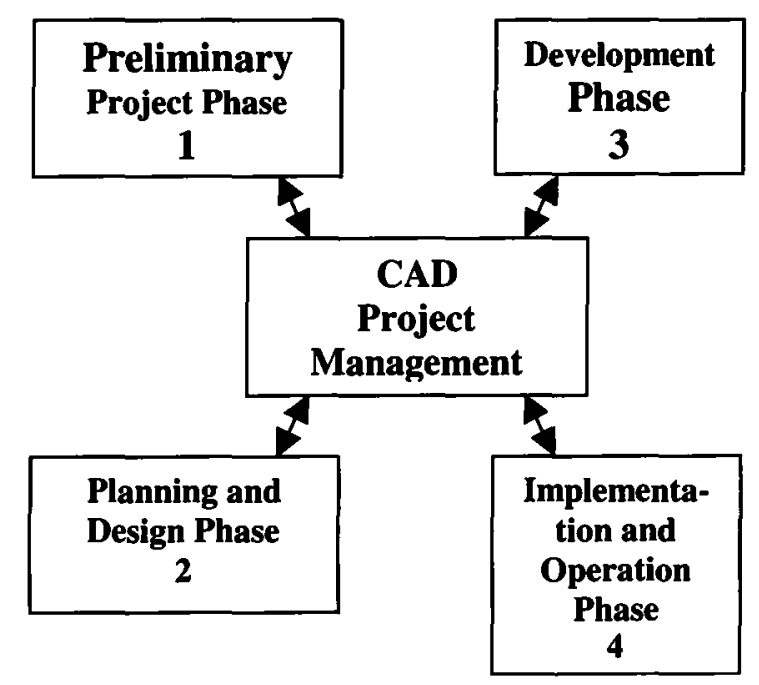

CAD project life cycle

Usage of project management methodology becomes a reality of our days for most of IT projects. Although project management methodology is invariant toward project scope, it is necessary to take into account some peculiarities of IT sector of CAD systems. An effective project management supposes the systems approach to a project and its environment which is based on a variety of factors such as financial, time, organisational, technical ones, etc. Systems analysis allows to evaluate a project from different points of view - technical, economic, organisational and commercial.

Technical component of CAD strategy includes forming hard and software decisions developing information system and methodology of CAD.

Economic component of CAD strategy allows to determine economical expediency of accomplishing different project alternatives and to check their stability toward changes of costs and benefits.

Organisational component of strategies supposes that a chosen CAD strategy fits business processes of design organisation.

Commercial component of strategies at preinvestment phase of CAD project life cycle includes marketing research of CAD products and services.

Forming and selecting CAD information strategies embrace systems analysis of technical, organisational and commercial components of computerisation process of construction design, development of CAD project management methodology based on project management and business process reengineering principles forming a set of strategies of CAD project and a way of selecting rational information strategy for a design company accord- ing to technical, economic and organisational conditions of its functioning and economical and commercial criteria.

The outline structure of algorithm of forming and selecting $C A D$ information strategies have been proposed, it can serve as a foundation for CAD information strategy development in a given design company.

Forming and selecting CAD information strategies for construction objects are mostly predetermined by development of norms- and rule-making base in construction sphere, which influences economic and commercial components of CAD strategies.

\section{Norms- and rule-making within information sup- port of innovation development in construction}

Technical advance in construction, change of economic and legal mechanisms call for systems engineering-based development of regulatory basis (norms, rules and other documents). Regulatory basis in construction is formed in the process of norms- and rule-making and is predetermined by scientific and technical progress [10].

Until now there is not a single definition of norms and rules as well as of a variety of terms and notions based on them. Let's agree that norms and norm-making go to production and technical sphere while rules and rule-making belong to technical-economical-social sphere. Norms- and rule-making put together law-making which creates a regulatory basis of construction.

Efficiency of this process organisation depends mostly on information support necessary for it which must be constantly updated by innovations in construction science and practice.

Information technologies must guarantee the quality of regulatory support, horizontal and vertical matches between norms and regulations at every level.

It is scientific and technical basis which is fundamental for innovation interrelations of rules and norms. Norms as well as laws determine the activities in construction sphere and their results based on scientific and technical progress (STP), they are changed and improved because of STP influence. Norms go after laws, and laws take into account STP by means of norms.

Time-dependent interrelations of norms and laws with STP determine their quality and topicality comparing with the current level of innovations. While in power, laws and norms begin to become ignorant about innovations. And unchanged laws and norms do not allow construction production to improve as fast as innovations.

That is why laws and norms improvement leads to STP based on innovation achievements that until recent time were late to technical norms, production and lawmaking.

Analysis of innovation-time interrelations of main stages (Innovations-Norms-Production-Laws) of normsand law-making allows to propose a hypothesis on overlapping of these stages and reducing the way of innova- 
tion toward norms and laws using information technologies allowing to give an information on innovations as an input to norms- and law-making process.

Information and intellectual technology of regulatory support may be based on general CAD structure which is formed of different models and includes predesign stage of evaluation as well as stages of analysis and target forming of conception at computer workstations, decision preparation and support.

It is suggested to include a forecasting subsystem into the whole decision support system created using CAD. This subsystem makes a connection between norms- and law-making that are far away from each other in modern construction regulatory support sphere. Monitoring allows to accumulate information on innovations in construction, and a potential volume of innovations gives possibilities to forecast a critical mass of news and achievements in STP which predetermines a necessity in changing and improving the construction norms and laws.

Different types of innovations need different types of information support for normative documents formed by specialists with different backgrounds from different agencies, ministries, organisations. As well as CAD information strategies development, norms- and law-making uses hardly formalised information from different scopes. Hence we need special methods of its processing and transformation, and one of them is neurosemantic method of forming conceptual decisions in construction.

\section{Neurosemantic method of forming conceptual decisions in construction}

Stage of macrodesign of construction systems is characterised by dynamics of data changes, data incompleteness, data originality and large and extra large data flows that cannot be formally structured (Table).

It is important that conceptual decisions in construction cannot be made based on cut-and-try method, hence the only way left is modelling and forecasting.

The research done allowed to formulate the main principles of design and analysis of conceptual decisions for construction systems:
1. According to the systems engineering approach, a conceptual decision is considered as a system of interrelated activities accomplished as a complex leading to determined goals, ie to the result that is a systems-forming factor.

2. From a formal point of view, conceptual decisions are coherent texts or texts fragments in natural language, and it is necessary to use methods of computeraided texts processing and semantic modelling.

3. Effective method of conceptual decisions research is structure exposure. By structure model we chose a model containing elements of two types: actions (events) and connections among them. Elements of the first type can be divided into goals, outer factors, and actions taken during conceptual decision achievement.

4. Elements of the first type are presented as words, word combinations, expressions, notions in natural language, these elements are called cognitive elements or concepts.

5. Research of structure model has to be done in two dimensions - static and dynamic analysis.

6. For the analysis of approaches to determination of relationships between fragments of coherent texts let us identify a logic-semantic modelling as the most effective method of exposure of second type elements (as one of semantic modelling methods) $[14,15]$. It allows to get static characteristics of conceptual model for construction system and method of information presentation by cognitive maps for developing a model for accomplishing dynamic analysis using the neuronet technology.

Forecasting of conceptual decision achievement is done by presenting a structure model as a cognitive map from which it is possible to move to the neuronet presentation [15].

Every relationship in a cognitive map is determined as positive or negative depending on direct or inverse mathematical relations between elements. An element of a cognitive map becomes a neuron, and a matrix of relationships becomes a matrix of synaptic weights. By activating one or several elements we can get a reaction of other elements of a neuronet, some of them will not react, while others will change positively or negatively.

The main stages of the method developed

\begin{tabular}{|c|l|l|l|l|}
\hline No & \multicolumn{1}{|c|}{ Stage } & \multicolumn{1}{|c|}{ Result } & \multicolumn{1}{c|}{ Tools } & \multicolumn{1}{c|}{ Resources } \\
\hline 1 & $\begin{array}{l}\text { Determination subgoals } \\
\text { (tasks) and necessary } \\
\text { activities }\end{array}$ & $\begin{array}{l}\text { Set of elements of } \\
\text { conceptual model }\end{array}$ & $\begin{array}{l}\text { Expert methods, text } \\
\text { processing programs }\end{array}$ & Experts, program operators \\
\hline 2 & $\begin{array}{l}\text { Determination of relations } \\
\text { between elements }\end{array}$ & Structure of target program & $\begin{array}{l}\text { Semantic modelling (logic- } \\
\text { semantic models, cognitive } \\
\text { maps) }\end{array}$ & $\begin{array}{l}\text { Analysts, knowledge } \\
\text { engineers, computer }\end{array}$ \\
\hline 3 & Analysis of structure model & $\begin{array}{l}\text { Determination of the most } \\
\text { important elements, } \\
\text { decomposition, evaluation of } \\
\text { subsystems and their } \\
\text { relations. } \\
\text { Forecasting for development } \\
\text { of construction system }\end{array}$ & Theoretical-graph methods & $\begin{array}{l}\text { Computer-aided processing, } \\
\text { probably with a help of } \\
\text { knowledge engineer }\end{array}$ \\
3.1 & Static analysis & Dynamic analysis & Neurotechnologies & \\
\hline
\end{tabular}


Extrapolating neuronets, a kind of associated memory models are used here (one-layer with back connections - Hopfield nets). As distinct from multilayer nets, Hopfield model's neurons are input, hidden and output simultaneously. The input is a beginning configuration of neurons activity, the output is a terminal steady configuration of their activities.

The input is an input image $\mathrm{A}=\left[a_{1}, a_{2}, \ldots, a_{n}\right]$, where components (a set $R_{k}$ ) are determined while others are not.

A net reconstructs those components according to the following algorithm:

1. Starting initialisation of neurons

$$
b_{i}^{o}=\left\{\begin{array}{l}
a_{i}, i \in K \\
0, i \notin K
\end{array}\right.
$$

2. Calculation of new stages of neurons for all $i \notin K$ is made according to formula:

$$
b_{i}^{m+1}=f\left(\sum_{i=1}^{n} b_{i}^{m} W_{i j}\right),
$$

where $f$ - step function of activation taking a meaning +1 or -1 ;

$W_{i j}$ - a weight of synaps connection of neuron $i$ to neuron $j$. tion, ie

3. Step 2 is made until a net is in a stable condi-

$$
b_{i}^{m+1}=b_{i}^{m} .
$$

The output analysis includes:

1. Analysis of goals achievement - output conditions of elements have to be positive;

2. Analysis of actions - output conditions of elements of a set of actions may be positive which indicates that modelled input situation positively influences the given action accomplishment, or negative which means that given action will be not accomplished in a modelled situation.

A correction can be made by adding new elements positively influencing the problem elements.

Suggested neurosemantic method of modelling construction systems can be efficiently used at macrodesign stage, when CAD information strategies and information support of innovation development are created.

\section{Conclusion}

The importance of systems engineering will increase because of the need in creation of a large number of different construction systems. That is why, there is a demand in active development of systems engineering in construction as a scientific-engineering methodology of efficient design, construction, operation of construction systems and intersystems relations that are of great diversity and individuality.

\section{References}

1. Gusakov A. A. Systems Engineering in Construction. Moscow: Stroyizdat, 1983. 440 p. (i

n Russian).

2. Systems Engineering. Ed by Gusakov A. A. Moscow: "New Century" Fund, 2002. 768 p. (in Russian).

3. Gotlieb C. C. The Economics of Computers: Costs, Benefits, Policies, and Strategies. Prentice-Hall, NJ, 1985. $470 \mathrm{p}$.

4. Kovacevic A.; Majluf N. Six Stages of IT Strategic Management. MIT, Sloan Management Review/Summer 1993, p. 77-87.

5. Pinto J. K. Successful Information System Implementation: The Human Side. PMI, 1994. 220 p.

6. Schultheis R., Summer M. Management Information Systems: The Manager's View. IRWIN, 1995. $800 \mathrm{p}$.

7. Kulikova E. N. Neurosemantic Method of Computer-Aided. In: Design of Target Construction Programs. Systems Engineering. Ed by Gusakov A. A. Moscow: "New Century" Fund, 2002, p. 653-670 (in Russian).

8. Ilina O. N. Forming and Selection of CAD Information Strategies in Construction In: Systems Engineering. Ed by Gusakov A. A. Moscow: "New Century" Fund, 2002, p. 671-684 (in Russian).

9. Yetton Ph.; Kim J.; Craig J. Computer-Aided Architects: A Case Study of IT and Strategic Change MIT, Sloan Management Review/Summer 1994, p. 57-67.

10. Melikhova O. F. Information Support of Innovative Development in Construction. In: Systems Engineering. Ed by Gusakov A. A. Moscow: "New Century" Fund, 2002, p. $685-698$ (in Russian).

11. Grossberg S. Neural Networks and Natural Intellegence. Cambridge: MIT Press, 1988. 380 p.

12. Hopfield J.; Tank D. Computing with Neural Circuit: A model. Science. Vol 233, 1986, p. 625-633.

13. Cats-Baril W.; Thompson R. Information Technology and Management. IRWIN, 1997. $512 \mathrm{p}$.

14. Kosco B. Bi-directional associative memories IEEE Transactions on Systems, Man and Cybernetics, Vol 1, No 1, 1987 , p. $49-60$.

15. Kosco B. Fuzzy cognitive maps International Journal of Man-Machine Studies, Vol 24, 1986, p. 65-75. 